\title{
What Makes a Teacher a Special Needs Teacher? The Perspective of a Pedagogic Signature
}

\author{
Ewald Kiel, Markus Kollmannsberger, Thomas Lerche, Sabine Weiss \\ Ludwig-Maximilians University, Munich, Germany
}

\begin{abstract}
The goal of the study was to identify a pedagogic signature for teachers in special needs education. According to Shulman, a pedagogic signature can create a professional identity and provide guidance. The present study used a mixed-method approach. Experts in learning disabilities and emotional/ behavioral disorders completed an instrument from the field of industrial and organizational psychology that quantified and weighted professional demands on teachers. The results were added and validated with group discussions. By combining the results with Shulman's dimensions of a pedagogic signature, it is apparent that surface structure and deep structure play a minor role in special needs teachers' perceptions. The importance of an implicit structure in terms of a particular humanistic ethos is characteristic of special needs education. The consequences for the practice of teaching will be considered in terms of current problems and questions in research and practice, and particularly regarding inclusion.
\end{abstract}

\section{Introduction}

Each profession seeks to initiate future practitioners in a certain way and manner to their eventual professional field of action. An initiation like this is usually grouped around questions such as the following: What values should a professional have? How should a professional practice his or her profession? What beliefs should a professional hold? How does one encourage professionals to develop values, behavioral practices, and thought patterns during training? Answers to these questions provide a framework that guides novices' perceptions, interpretations of situations, and actions in their professional life. Moreover, these questions help experts reflect on their actions, to give reasons for their actions, or to create obligations that must be fulfilled by peers or novices. In other words, finding answers to these questions reduces uncertainty and is a starting point for creating a professional identity [1] or a professional vision [2].

Lee S. Shulman, the former president of the Carnegie Foundation for the Advancement of Teaching, claims that questions such as these are much more difficult to answer for professionals in education than for other professions such as law or medicine [3] [4]. The internationally influential American scientist initiated an international debate on this lack of educator professionalism that resonates to this day [5]. At the center of this debate is the term "pedagogic signature" coined by Shulman. He characterizes this signature, which is the core of a professional identity or vision, in three dimensions:

- Surface structure: "concrete, operational acts of teaching and learning, of showing and demonstrating, of questioning and answering, of interacting and withholding, of approaching and withdrawing."

- Deep structure: "a set of assumptions about how best to impart a certain body of knowledge and know-how."

- Implicit structure: "a moral dimension that comprises a set of beliefs about professional attitudes, values, and dispositions" (p. 55) [5].

This article is about the development of a pedagogic signature for special needs education. To develop this signature, we briefly introduce a definition of special needs and the structure of special needs education in Germany. Second, we characterize the structure of professional teacher action in terms of a general pedagogic signature for teachers. Both steps are necessary, because they represent underlying conceptions or structures of the empirical research carried out in Germany. Third, we present our scientific investigation and characterize the pedagogic signature of special needs education. Fourth, we discuss our findings.

\section{Special needs education in the German framework}

In the framework of the German school system, special needs education is defined as "limitations of children and adolescents in personal development and learning which require particular educational measures beyond regular education" [6]. The term "particular educational measures beyond regular education" also touches upon issues such as equity, participation, respect for diversity, sustainability, marginalization, etc. To some extent, this definition is compatible with definitions in the Anglo-Saxon scientific community [7]. 
Not as compatible as this definition is the structure of special needs education in Germany. Currently, it is segregated education. There are different schools for students with special educational needs. One group of schools is for students with physical disabilities, e.g., hearing or visual. Another group is for students with cognitive or social behavioral problems. The ratification of the UN Convention of the Rights of People with Disabilities in 2008 has initiated intense discussions about how to break up the segregated German school system and create an inclusive system. Thus, this research takes place at a turning point for the German educational system.

\section{Elements of a general pedagogic signature for teachers}

Another underlying conception of our research are the theoretical and empirical findings on teachers' professional actions. We summarize the tremendous number of findings very briefly in a chart inspired by Porst [8]. This chart is the first step toward a pedagogic signature for teachers in general. We will revise this chart two times during this article until we reach the pedagogic signature for special needs education.

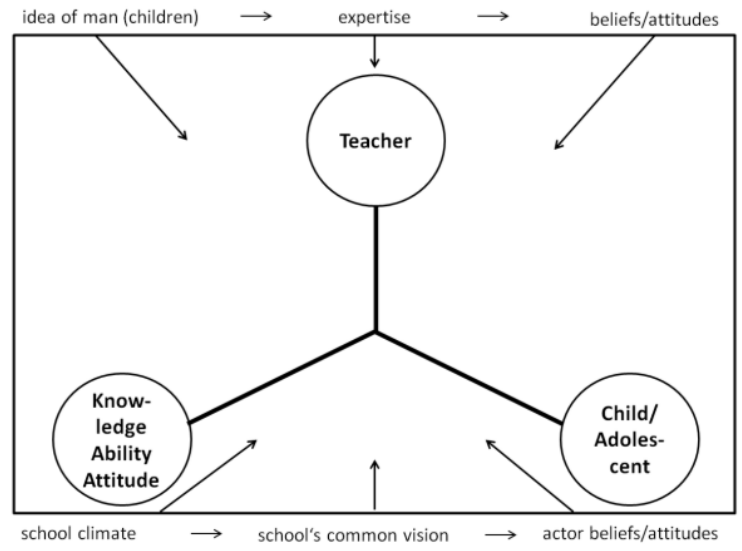

Figure 1. Basic theoretical and empirical aspects of a general signature for professional teacher action

The inner part of the rectangle consists of the "classical triangle" of "teacher," "child/adolescent," and "knowledge/ability attitude." We call it "classical" because it has been presented to German teacher students in different variations for more than 150 years since the period of Johann Friedrich Herbart (1776-1841), the founding father of systematic studies in education in Germany, and it is still a subject of scientific discussion. The original idea is that teacher must impart knowledge, abilities, and attitudes to children and adolescents. However, the triangle also represents the basic idea of teacher effectiveness research. The instructor is supposed to arrange knowledge, ability, and attitude in such a way that they can be processed and understood by the individuals who are supposed to learn something from the instruction. However, in the American tradition, the term "didactic," which is popular in German-speaking countries, Scandinavia, and China, is not used, because the term has a negative connotation. This process in the triangle is heavily influenced by the aspects at the upper and lower sides of the surrounding rectangle:

- Idea of man (children): E.g., if one follows the spirit of John Dewey's "Democracy and Education" [9], children should develop into democratic citizens; therefore, the process of imparting knowledge should take place in a democratic environment, it is value driven by democratic ideas, and students should have possibilities to develop to autonomous society conscious persons, etc.

- Teachers' expertise: The expert novice paradigm is a broadly discussed theory on teacher professionalization. Expert teachers are supposed to organize the process of teaching and learning differently, because experts have, in contrast to novices, stored experience and usable knowledge about the core duties of a teacher, profound, domain-specific insight as well as efficient problem-solving [10]. Thus, expert teachers interpret situations better, are more flexible, have more automatic routines, and can deal effectively with unforeseen events. Experts' problem understanding is more oriented toward students' needs and the classroom environment.

- Teachers' beliefs/attitudes: In modern research on education, beliefs and attitudes are about subjective conceptualizations of a teacher's role, the nature of teaching and learning, the educational system, and cultural or societal values [11] [12] [13]. Thus, a teacher who believes that the nature of teaching consists of what behaviorism teaches us will arrange learning situations differently from someone who believes in superlearning. Beliefs and attitudes filter our perception, motivate us, and influence regulation and self-regulation.

- Actor beliefs/attitudes: Not only teachers have beliefs about their role, the nature of learning, etc. Learners also have beliefs and are influenced by them.

- School climate: In German-speaking countries, research on school climate is also very prominent and has several commonalities with Anglo-Saxon research [14] [15]. The idea following from this research is that in a functioning school community based on mutual respect students become more altruistic, develop social and emotional competencies, are more performanceoriented, and display less unfavorable behavior. 
- School's common vision: A school's common vision is closely linked to ideas about the school climate. A common vision is an important contributor to the school climate.

What conclusions can be drawn from this sketch in order to conceptualize professional teacher action? First, the relationship between "teacher," "knowledge, ability attitudes," and "child/ adolescent" is not unidirectional. Metaphorically speaking, this means that it is not the teacher who works something into the head of the children. The development of knowledge is conceptualized as interaction. This idea is heavily influenced by conceptualizations of the child/adolescent as an agent of knowledge construction and goes back to the German enlightenment, progressive education (partly in the tradition of Dewey), modern constructivism, etc. This interaction is guided by values such as mutual trust and relationship, community orientation, and care. Research on school climate and common vision has pushed forward ideas like this. From a rational goal-oriented perspective as the expert-novice paradigm, teachers are supposed to have expertise in media and teaching methods, planning and conducting lessons, and managing the classroom. Thus, our first chart can be supplemented in the following way:

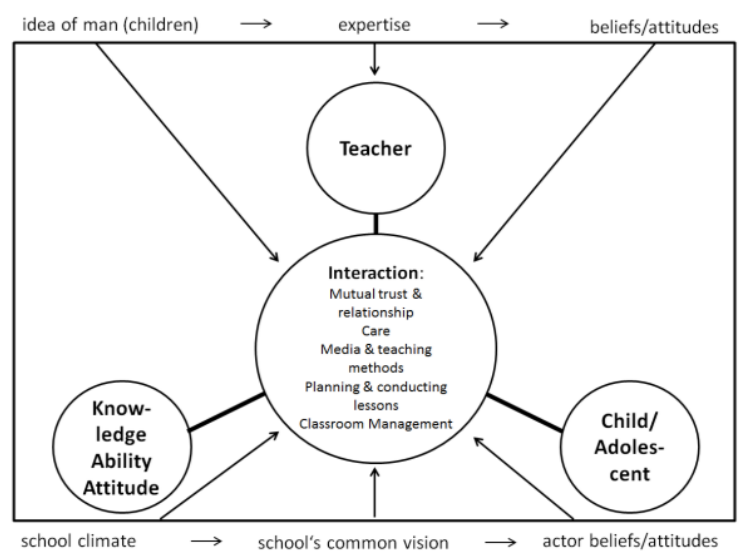

Figure 2. Revised chart of a general signature of professional teacher action

Through our research on a pedagogic signature of special needs education presented in the following chapter, we will revise this chart.

\section{Questions}

Based on the existing theoretical and empirical findings, we focus on the following research questions:

1) What does the pedagogic signature of a teacher in the special education area look like?

2) What subject knowledge and which social and personal skills are required to practice the profession or are part of the pedagogic signature?

3) Are there different pedagogic signatures for work involving students with learning disabilities than for work involving students with emotional/behavioural disorders?

\section{Methods}

\subsection{Project and Research Context}

The goal of the project is to establish school-form specific demand profiles with an emphasis on traits and qualities, based on data collected from various groups of experts. The demand profile created for the teaching profession will flow into Project Risk-Check for Prospective Teachers in the sense of a Realistic Job Preview - an instrument that should support teacher trainees before and during their studies and assess the individual expectations, motives and wishes of the students with regard to their studies and future professions, thereby providing empirically-founded evidence for their career choices.

\subsection{Random Sampling}

In line with the process of analysing demands (e.g., in industrial and organizational psychology), experts from various levels of the education sector were recruited, including those involved in teacher education and those working in the practical field. Only those experts who had been active in the teaching profession for six years were asked to participate.

The total sample included 72 experts with the following distribution:

- 38 experts employed in the learning disability sector

- 34 experts employed in the emotional/ behavioural sector

Half of the experts in each area were teachers involved in the training and mentoring of prospective teachers; the other half were not.

For the group discussions, the experts were divided into twelve homogenous discussion groups (table 1).

Table 1. Composition of the discussion groups

\begin{tabular}{|l|c|c|c|c|c|c|}
\hline & gr 1 & gr 2 & gr 3 & gr 4 & gr 5 & gr 6 \\
\hline learning disabilities & 5 & 6 & 7 & 7 & 7 & 6 \\
\hline $\begin{array}{l}\text { emotional/behavioral } \\
\text { disorders }\end{array}$ & 5 & 5 & 4 & 7 & 6 & 7 \\
\hline
\end{tabular}




\subsection{Measuring Instruments and Procedure}

In this study the strengths of both qualitative and quantitative methods (completeness, weighted evidence, communicative process) were used in a mixed-method approach [16] of the data to consider the following:

- Can commonalities be found in the demand ratings for the use of two methodical yet differing approaches?

- Are there differences in the qualitative and quantitative investigations? How can these differences be explained?

- Are there demands that were not incorporated into the qualitative measurement?

\section{i. Quantitative Data Collection and Analysis}

Development of the Measuring Instrument. Worldwide, one of the most applied instruments in creating a demand profile analysis is the FleishmanJob Analysis Survey (F-JAS) [17]. In order to modify this instrument for use in the education profession, two pre-tests with a total of twelve teacher education experts were conducted before the study began. In these expert rounds, items that were exclusively comprised of technical content were eliminated, and items that, according the majority opinion of the experts, were especially relevant to the teaching profession were added. As a result, the instrument of quantitative assessment comprises 98 items. The techniques used by the F-JAS were applied for the survey: the experts rated the different demands for carrying out instruction on a scale from one to seven.

Analysis. A total of 7056 ratings were collected from the 72 experts (in the area of learning disabilities, $\mathrm{n}=3724$; in the area of emotional/behavioural disorders, $\mathrm{n}=3332$ ). These individual ratings were computed into a score value (numerical medium for the ratings). The analysis of these expert ratings with the significance of the individual items of the modified F-JAS shows the following results regarding the estimation of importance:

- The instrument contains occupational demands only and avoids correction or reference items; therefore, all items have a negative skewness ( median $=-0.40 ;$ range $=[-1.41 ; 0.36])$.

- For the same reason, with the help of the quartiles and the kernel density estimator, a clear ceiling effect can be verified for most items.

- By answering the first items, the individual expert established an implicitly individual frame of reference, to which he or she adjusted his or her further estimations (individual intercept). Experts who rated the initial items relatively highly tended to compare all aspects that followed to their previous estimations and to correspondingly adjust the resulting estimations of importance. These individual biases can be verified through comparison with the respective general linear models $(\mathrm{F}(97,6853)=29,7$; $\mathrm{p}<$ $.001, \mathrm{R} 2=.30$, and scoreValue $\sim$ Item + Expert $(\mathrm{F}(167,3783)=34,6 ; \mathrm{p}<.001, \mathrm{R} 2=.47)$ and must be considered in further analysis.

In unbiased estimates of a value through models in which constant (here: item estimation) as well as random (here: experts) effects are significant, the use of a mixed linear model is recommended [18]. Therefore, a Random-Intercept Model is used to approach the expert regarding his or her individual adjustment as an incidental estimator. This adds an individual bias $(\mathrm{SD}=.49)$ to the results, which is adjusted as a correction factor in the estimation of the score values. The additional necessary calculations are conducted using the statistical tool $R$ and the library lme4.

These adjustments produce an improvement in the stability index of the favoured initial model in order to estimate the score value $\left(\mathrm{R}^{2}=.35\right)$. Nevertheless, even after the adjustments were made, a negative value remained for practically all items in the distribution skew $($ Median $=0.30$; Range $=[1.14$; 0.47]). The ceiling effect can be lessened through the adjustment but cannot be eliminated, so further results were analysed with distribution-free methods. The Intra-Class Correlation (ICC) (average, 2factorial, adjusted) is $\operatorname{ICC}(3, \mathrm{k})=.96$, which is a good value due to the range of the skewness being nearly 2. (This is a minimum estimation, since various negative skewnesses have a negative influence on the estimation of the ICC.) Further findings were examined using distribution-free procedures.

\section{ii. Qualitative Data Collection and Analysis}

Qualitative Procedure. According to Lamnek [19], the opinions and attitudes of a whole group may be garnered through investigative group discussions. This approach allows the creation of a pedagogic signature in the sense of a collective pattern for orientation. In contrast to a quantitative approach, group discussions permit verbal legitimation and clarification by experts. Furthermore, more opinions surface in group discussions than in solely quantitative inquiries as a result of mutually stimulating conversation. Results collected by conjointly determining a pattern of orientation are deemed valid.

The course of the discussion is thematically structured with reference to the following key questions: 
- Which qualities and skills should a teacher possess in order to carry out his or her work?

- Which qualities and skills are especially important?

The statements and opinions were initially compiled in writing (moderation cards) and made visible for all participants. In the discussion, attempts were made to highlight opinions through mutual conversation and to reach a consensus through collective mind-mapping. Each discussion group was monitored by experienced individuals currently active in teacher education. Protocol was collected by another teacher educator.

Analysis. The analysis is oriented toward the theory of qualitative content analysis according to Mayring [20]. The goal of an analysis is to reduce the material so that the fundamental content remains and to obtain through abstraction a straightforward corpus which remains an image of the raw material. The statements received during protocol by the participants were ordered into categories with the help of the MaxQDA program. Therefore, a theoretically based category system was developed from the material. Without being asked, the overwhelming majority of the discussion participants made reference to the well-established differences regarding the abilities and traits in the categories of subject, method, social and personal competencies.

The Interrater Reliability was calculated to verify the quality criteria. In addition, the demands specified by teachers were completely doubly encoded. Consensus was reached when at least $90 \%$ of the relevant passages were identically coded. In the literature, a reliability coefficient of .70 overall is seen as satisfactory [21].

\section{Results}

\subsection{Demands in Special Needs Education - Quantitative Analysis}

The expert rankings were adjusted according to intercepts and arranged into a table. There were no great gaps between the score values in the overall ratings or in the differentiation of the estimations of importance. Thus, the descriptions of importance were reference-free and established solely according to place ranking. The following formulation was used:

- Very important: Place ranking 1-10

- Important: Place ranking 11-20

- Worthy of consideration: Place ranking 20-35

- Of average importance: Place ranking 36-74

- Rather unimportant: Place ranking 75-98

The entries according to the various sectors will be itemized below to illustrate a differentiated view of the similarities and differences between the learning disabilities and emotional/behavioural disorder sectors. The significance of the differences between the individual sectors will be verified with the help of the Kruskal-Wallis Test. This verification will not be made according to place ranking, but rather according to the actual score values of each item. This method provides more conservative estimates (due to the ceiling effect) than testing the differences of the place ranking would.

The following aspects, which are consistent to both areas (learning disabilities as well as emotional/behavioural disorders), are deemed to be very important:

1) Child-centeredness (To get a feeling of enjoyment when interacting with children and youth);

2) A caring leadership style (To recognize each person present, to take the person's needs and emotions seriously, and to show interest in the person);

3) Social sensitivity (To respect and understand the feelings and viewpoints of others, and to estimate the consequences of actions on others);

4) Attentiveness and focus (To remain equally attentive to various aspects of the environment, the person and the behaviour, and to show attentiveness and awareness of these aspects);

5) Authenticity (To appear as if one's rational, emotional, verbal, non-verbal, visible and nonvisible signals and information have an overall cohesion);

6) Resistance to stress (The ability to stay healthy and reach one's pre-set goals during difficult, wearing and stressful situations).

Table 2 shows the value rankings of the aspects mentioned above. No significant differences exist between the areas of learning disabilities and emotional/ behavioural disorders.

Table 2. Ranking of demands unanimously named as very important

\begin{tabular}{|l|c|c|c|}
\hline Demand & $\begin{array}{c}\text { learning } \\
\text { disabilities }\end{array}$ & $\begin{array}{c}\text { emot./behav. } \\
\text { disorders }\end{array}$ & $\chi \mathbf{2}$ \\
\hline Child-centeredness & 1 & 1 & $3.95 ;$ n.s. \\
\hline $\begin{array}{l}\text { A caring leadership } \\
\text { style }\end{array}$ & 2 & 2 & $3.24 ;$ n.s. \\
\hline Social sensitivity & 3 & 4 & $0.71 ;$ n.s. \\
\hline $\begin{array}{l}\text { Attentiveness and } \\
\text { focus }\end{array}$ & 4 & 10 & $0.51 ;$ n.s. \\
\hline Authenticity & 6 & 6 & $0.42 ;$ n.s. \\
\hline Resistance to stress & 7 & 8 & $0.02 ;$ n.s. \\
\hline
\end{tabular}

The following aspects are either (a) regarded by one group as "very important" and regarded by the other group as merely "important" (1-7) or (b) regarded by both groups as "important" (8-11): 
1) The ability to resolve conflict (To resolve disputes, including the ability to find a compromise and mediate a dispute);

2) Flexibility (To adapt to suddenly changing, unplanned situations; this includes grasping and appraising new situations in as short a time as possible);

3) Communicative ability (To express oneself verbally in words and sentences that others can understand);

4) Ability to balance private life and work (To attain long-term satisfaction from a balanced relationship between work and private life; this includes managing stressful situations at work with partnership, family or free-time activities);

5) The creation of learning opportunities (To prepare and put into practice child-appropriate learning opportunities);

6) Approach to heterogeneity (To be able to work with the differences of group members; this includes being able to use the diversity and distinctiveness of the group to advantage in order to work productively);

7) Providing feedback (To clarify in a respectful manner how performance, behaviour and demeanour are perceived, understood and assessed);

8) A demeanour of confidence (To show and communicate self-confidence in social situations);

9) Identifying behavioural patterns (To recognize recurrent behaviours and be able to classify them);

10)Durability (To be able to recover the same energy and enthusiasm after a discouraging situation);

11) The ability to maintain a distance (To be able to separate from the daily work routine and work-related problems, be able to "turn off").

Table 3 shows the value rankings of the abovementioned aspects.

Table 3. Ranking of the demands estimated as very important or important

\begin{tabular}{|l|c|c|c|}
\hline Demand & $\begin{array}{c}\text { learning } \\
\text { disabilities }\end{array}$ & $\begin{array}{c}\text { emot./behav. } \\
\text { disorders }\end{array}$ & $\chi \mathbf{2}$ \\
\hline $\begin{array}{l}\text { Ability to resolve } \\
\text { conflict }\end{array}$ & 5 & 15 & $3.02 ; \mathrm{n} . \mathrm{s}$. \\
\hline Flexibility & 8 & 12 & $0.86 ;$ n.s. \\
\hline $\begin{array}{l}\text { Communicative } \\
\text { ability }\end{array}$ & 9 & 11 & $0.01 ;$ n.s. \\
\hline $\begin{array}{l}\text { Ability to balance } \\
\text { private life and work }\end{array}$ & 11 & 9 & $0.42 ;$ n.s. \\
\hline $\begin{array}{l}\text { Approach to } \\
\text { heterogeneity }\end{array}$ & 15 & 3 & $7.97 ; \mathrm{p}<.001$ \\
\hline $\begin{array}{l}\text { The creation of lear- } \\
\text { ning opportunities }\end{array}$ & 13 & 5 & $3.45 ;$ n.s. \\
\hline
\end{tabular}

\begin{tabular}{|l|c|c|c|}
\hline Providing feedback & 18 & 7 & $1.36 ;$ n.s. \\
\hline $\begin{array}{l}\text { A demeanor of } \\
\text { confidence }\end{array}$ & 10 & 17 & $2.59 ;$ n.s. \\
\hline Demand & $\begin{array}{l}\text { learning } \\
\text { disabilities }\end{array}$ & $\begin{array}{c}\text { emot./behav. } \\
\text { disorders }\end{array}$ & $\chi \mathbf{2}$ \\
\hline $\begin{array}{l}\text { Identifying } \\
\text { behavioral patterns }\end{array}$ & 12 & 19 & $4.15 ; \mathrm{p}<.05$ \\
\hline Durability & 17 & 16 & $0.08 ;$ n.s. \\
\hline $\begin{array}{l}\text { Ability to maintain a } \\
\text { distance }\end{array}$ & 19 & 18 & $2.71 ;$ n.s. \\
\hline
\end{tabular}

It is important to note the significantly stronger assessment of the importance for knowledge of behavioural patterns in the work with students with learning disabilities and the greater emphasis on an approach to heterogeneity in the area of emotional/behavioural disorders.

\subsection{Demands in Special Needs Education - Qualitative Analysis}

The results of the group discussions were combined to form categories. Table 4 provides these categories once more. In the following, the categories will be explained and illustrated with contributions from the discussion.

\section{i. Social Competences}

Basic leadership ability is described as finding a balance between instruction and space for autonomy. An enjoyment of interacting with children and young people and empathy are necessary in order to engage with the students and their specific problems and to face them appreciatively. Ability to bond with others means being "closely tuned in with the students. Often the teacher is one of the most important or even the most important person in the students' lives, the teacher has much more access into the private lives of the students. Education can only work if there is a relationship." Social sensitivity is also helpful.

The panel also designates communication skills as crucial. Teachers in the area of learning disabilities define this trait as having a clear but adaptable language and expand the definition to include oral and written articulation skills. Integrated therein are, for example, the ability to create "reports without linguistic shortcomings" and the ability to hold a conversation. In this context, cooperation is emphasized. This is defined as teamwork within the school, cooperation with external actors (e.g., doctors, police, child services), and functioning in networks of great importance. In the area of emotional/behavioural disorders, reference is made to the ability to act accordingly. This is defined as reacting to acutely hazardous situations and having the ability to de-escalate. It includes strategies and tools for operating in every crisis situation: "One 
should not feel helpless; you have to believe you are capable of action and have to be able to deal with the consequences of your actions."

Table 4. System of categories for the demands

\begin{tabular}{|c|c|c|}
\hline \multirow[t]{2}{*}{ Category } & \multicolumn{2}{|c|}{ Mentions } \\
\hline & $\begin{array}{c}\text { learning } \\
\text { disabilities }\end{array}$ & $\begin{array}{l}\text { emot./behav. } \\
\text { disorders }\end{array}$ \\
\hline \multicolumn{3}{|l|}{ Social competences } \\
\hline Leadership ability & 9 & 6 \\
\hline $\begin{array}{l}\text { Enjoyment of interacting with } \\
\text { children and young people }\end{array}$ & 11 & 12 \\
\hline Empathy & 8 & 10 \\
\hline Ability to bond with others & 6 & 8 \\
\hline Social sensitivity & 12 & 8 \\
\hline Communication skills & 10 & 5 \\
\hline Cooperation & 10 & 5 \\
\hline The ability to act accordingly & 0 & 6 \\
\hline \multicolumn{3}{|l|}{ Personal Competences } \\
\hline Authenticity & 11 & 8 \\
\hline Self-efficacy & 4 & 8 \\
\hline Resistance to stress & 10 & 9 \\
\hline $\begin{array}{l}\text { Ability to balance private life } \\
\text { and work }\end{array}$ & 8 & 8 \\
\hline Ability to maintain a distance & 4 & 5 \\
\hline $\begin{array}{l}\text { Openness to change/new } \\
\text { experiences }\end{array}$ & 0 & 5 \\
\hline Flexibility & 12 & 4 \\
\hline Authenticity & 11 & 8 \\
\hline Ability to reflect & 5 & 10 \\
\hline Attentiveness and focus & 5 & 6 \\
\hline A demeanor of confidence & 3 & 5 \\
\hline Reliability & 5 & 5 \\
\hline Self-organization & 8 & 5 \\
\hline \multicolumn{3}{|l|}{ Subject-/Method competences } \\
\hline Creating contexts for learning & 2 & 2 \\
\hline Imparting knowledge & 2 & 0 \\
\hline Special education knowledge & 5 & 5 \\
\hline Approach to heterogeneity & 5 & 3 \\
\hline Attitude/Professional Ethos & 13 & 14 \\
\hline
\end{tabular}

\section{ii. Personal Competences}

Authenticity means "standing behind one's convictions, with one's constitution being equal to one's actions." This is also reflected in self-efficacy: "You have to have the feeling of being able to help, of being certain, of remaining effective in crisis situations". Students often progress very slowly; many experiences of powerlessness occur," therefore, there has to be a "sense experience". Resistance to stress is considered highly important in the sense of psychological resilience and having strategies for coping with stress and balancing one's work and private life. In this context, the necessity of being able to keep a distance is emphasized. This includes "not taking personally what comes from the students" because "not being able to maintain a distance is like plunging into a piranha tank, and being eaten alive by the children."

Openness to new experiences, openness to change and flexibility are necessary, especially in relation to facing unexpected and unpredictable situations in the classroom. It should be "easy for teachers to manage in new situations" and "not panic." Similarly, the ability to reflect means the "perception of one's own strengths and weaknesses" and, thus, an awareness of one's self. Attentiveness and focus, reliability and a confident demeanour support "children lacking role models." This also means assuming responsibility for one's own actions, particularly in relation to students with emotional/behavioural disorders, the discussants emphasized. Self-organization is necessary mainly because of the increasing "challenges in the school system coupled with an increasing number of management activities. "It has been pointed out that acting in a system characterized by bureaucratic demands always offers room for manoeuvre."

\section{iii. Subject/Method Competences}

Subject-matter competence was briefly mentioned with regard to the creation of learning contexts: "I must be, as a teacher, in a position to create out of the curriculum topics and learning situations that might interest the children, build on their daily experience, and create situations that represent important life situations." Only one discussion group referenced imparting knowledge as a demand; thus, imparting knowledge was appreciated, but viewed as less important than social and personal skills. This assessment was presented as "a specific feature" of the profession. For special education knowledge, diagnostic, educational and psychological knowledge are more frequently named as demands. Reference was also made to the importance of approach to heterogeneity (e.g., with respect to balancing out the possibilities and associated costs of differentiation).

On the other hand, the subject competence of a characteristic in the special education area is subject to a change in terminology: "Subject knowledge is also present in the form of demands needed when working with students with special needs, it's just named differently there: The subject knowledge of special education teachers is the social competence."

\section{iv. Attitude}

The central element of the demand profile, which overrode all other areas, was attitude. Some discussants also used the term professional ethos. Attitude and ethos are to be understood in the sense of a positive view of human nature and a humanistic 
attitude, which "is extended to all other skills and qualities." This includes "acceptance" of the sometimes-difficult student clientele and never losing the necessary trait of "looking on the positive side:" "A deficit orientation often dominates; one only sees what children and young people are unable to achieve, what is not going well; often, behaviour is immediately blamed on the diagnosis previously made in a child. 'Looking on the positive side' means getting away from this deficit orientation and focusing on resources; it involves always looking out for what works for a child, what is there, what a child can do." This is considered a major challenge, as there is a very wide spectrum of clinical disorders. Since the children and young people involved have no lobby in society, one of the duties of teachers is "to give voices to all of the clinical disorders...giving voices to the ones who are depressed, the ones who are loud, etc." This includes accepting parents and understanding that, overall, students and parents have beliefs and attitudes that clash with the beliefs and attitudes of the teachers.

\subsection{Comparison of Quantitative and Qualitative Data}

On the one hand, using the mixed-method approach allows the development of a range of overlapping demands. On the other hand, aspects of the group discussions that are not reflected in the quantitative measuring instrument could result in differences in the range of demands.

The existing matching items can be summarized by the following key aspects:

- Demands that involve interaction with students are particularly important (e.g., the enjoyment of interacting, a caring leadership style, authenticity, the showing of attentiveness and focus).

- Communicative ability is crucial, and the group discussions specified this as using clear language, having written and verbal articulation skills, and being able to write reports.

- The demands relating to "health-promoting behaviour," such as stress resistance and balancing work and private life, were highlighted.

- Subject competences played a consistently minor role; in the quantitative measuring instrument, they were rated as rather unimportant, while in the group discussions they were spoken of as knowledge in diagnosis and social skills.

Differences in the spectrum of demands are due to additions and specifications in the group discussions. The group discussions highlighted important demands for working with students with special needs that were weighted lower by participants in the quantitative rating. These were:

- The ability to cooperate, both in the sense of team spirit in the school and of extracurricular cooperation with support services.

- Self-efficacy, the feeling that one has a purpose in life.

- The ability to act accordingly in acutely hazardous situations, a fundamental demand in the area of emotional/behavioural disorders.

The central demand - the attitude towards the students in terms of a humanistic ethos - was described only in the group discussions. Attitude was acknowledged as a key element overriding the other areas of competence of the demand profile. It is the "basis of the occupation". The value of the multimethod approach is shown here because, without including the collective orientation patterns from the group discussions, this important aspect would have been ignored.

\section{Discussion}

\subsection{What does the pedagogic signature for special needs education finally look like?}

According to the research results presented here, our first tentative model of a pedagogic signature of professional teacher action in general can now be specified for special needs teachers:

- As far as the value part is concerned, the most important specification is the humanistic ethos in terms of an orientation toward the potential of children/adolescents and not toward deficiencies. This ethos is part of the beliefs and attitudes in our chart. Views like this are supported by German authors as well as by authors in the Anglo-Saxon context [22] [23]. The humanistic ethos does not appear in the quantitative part, because no item referred to it. Thus, the mixedmethod approach has been proven seminal. However, the four most highly ranked abilities in the quantitative part, "child centeredness," a "caring leadership style," "social sensitivity," "attentiveness and focus," and "authenticity," can be understood as supporting or being the base of a humanistic ethos.

- At the expertise level, special needs teachers should have strategies for deescalating crises and are supposed to cope with everyday work and particular stressful situations by being able to distance themselves from stress and strain. Health research on teachers, which is very popular in Germany, confirms those findings [24]. Surprisingly, expertise in subject knowledge is mainly understood as knowledge in diagnosis.

- The level of interaction in our chart must be expanded. The quantitative and qualitative data mutually support the idea that teachers in special needs education are required to interact with their students based on the humanistic ethos. 
Moreover, interaction must be conceptualized beyond that what is going on in a classroom. Special needs teachers must cooperate not only with their colleagues but also with persons and institutions outside school. Although interaction has been shown to be crucial, it is characterized not by symmetric interaction but by an appreciative leadership style [25].

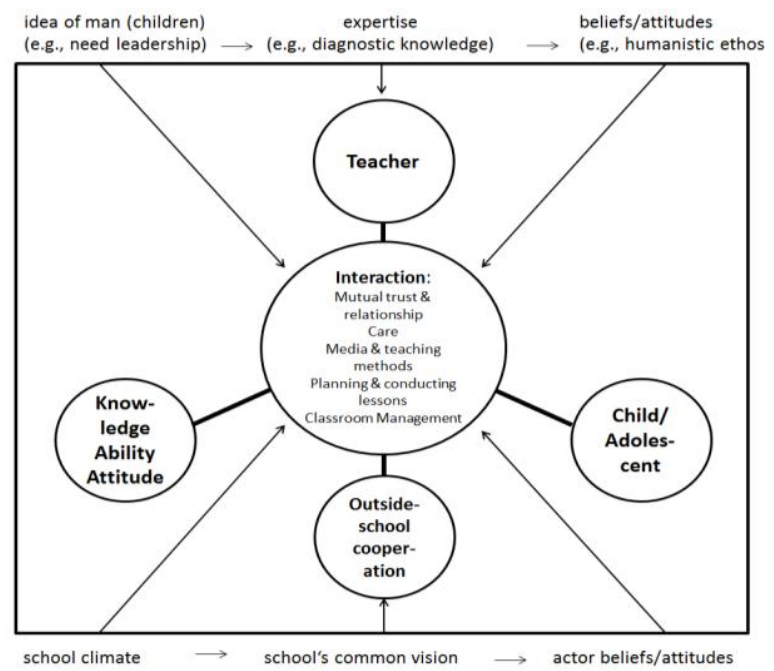

Figure 3. A pedagogic signature for special needs education

The rearrangement of the central chart of this article shows that scientific positions, as depicted in the first and second versions of the chart, can be complemented by asking professionals who work in the field. This complementing either highlights specific aspects or indicates a possible desideratum in conceptualizing professional action. Thus, science can be linked with the social practice of the organization of teaching and learning.

\subsection{Why are only some of Shulman's structural levels addressed in our research?}

From the perspective of Shulman's conception of a pedagogic signature, the implicit structure plays a major role whereas surface structure and deep structure play minor roles in special needs teachers' perceptions. How can this be explained?

In our opinion, the implicit structure in the qualitative part consists of the humanistic ethos; in the quantitative part, it is related to "child centeredness," a "caring leadership style," "social sensitivity," "attentiveness and focus," and "stress resistance." The aspects form a moral and ethical frame in the sense of Shulman that influences all teachers' actions. In the language of research on beliefs, this frame works as an evaluating filter for perception, regulation, and self-regulation [11] [12] [13]. This makes the filter function very powerful.
Thus, it is no surprise that experts asked about demands in professional teacher action refer to it. Shulman's most important structural dimension is located in the research on beliefs and values.

For surface structure, only "communicative ability" was identified as a member of this category. For deep structure, only "creating learning opportunities" was identified. Both aspects were viewed as significant only in the quantitative data.

At the heart of any pedagogic signature for special needs education, there is Shulman's implicit structure. Special needs education seems to be particularly value bound. However, surface and deep structure are not unimportant, but perhaps the high amount of individualization necessary in special needs education refers to elements of a surface and deep structure in group discussions difficult. Thus, we have only general references to "communicative ability" and "creating learning opportunities." We will address this question in future research by asking the discussion groups to specify surface and deep structure.

\subsection{What perspective does our research have for Germany and countries that have to establish an inclusive school system?}

With the ratification of Article 24 of the UN Convention on the Rights of Persons with Disabilities, Germany is one of many countries that find themselves at the beginning of making radical changes in the school system. Differentiated school systems must develop into inclusive school systems (see [23] [26]). A pedagogic signature for special needs education can help in this process because it

- conveys an identity for everyone involved in working with special needs students, which increases awareness of what is distinctive and meaningful in this profession. This is helpful for student teachers who are eager to acquire realistic insight into the demands of their future profession but also helpful for professionalization processes.

- provides guidance for teachers working in the inclusion. Particularly in Germany there is a shift of activity from regular schools to inclusive schools. Teachers who have thus far worked in the regular school system and feel deep-seated insecurity about inclusion due to inadequate training (e.g., see [27] [28]) need guidance because they do not have sufficient experience to deal with special needs problems.

- demonstrates the range of demands in special needs education to teachers and students, which is arranged around a fundamental value, the humanistic ethos. 


\section{References}

[1] van den Berg, R. (2002). Teacher's meanings regarding educational practice. Review of Educational Research, 72 (4), 577-625.

[2] Goodwin, C. (1994). Professional vision. American Anthropologist, 96, 606-633.

[3] Shulman, L.S. (2005a). Signature pedagogies in the professions. Daedalus, 134 (3), 52-64.

[4] Shulman, L. (2005b). The signature pedagogies of the professions of law, medicine, engineering, and the clergy: Potential lessons for the education of teachers. A speech delivered at the Math Science Partnerships Workshop: "Teacher Education for Effective Teaching and Learning" Hosted by the National Research Council's Center for Education. February 6-8, 2005, Irvine, California.

[5] Peel, D. (2011). Editorial: Signature pedagogies and the built environment. Journal for Education in the Built Environment, 6 (2), 1-7.

[6] Conference of the German Education Ministers (1994). Empfehlungen zur sonderpädagogischen Förderung in den Schulen in der BRD [Recommendations for special needs education in german schools]. Accessed January 28. http://www.kmk.org/fileadmin/veroeffentlichungen_beschl uesse/1994/1994_05_06-Empfehlung-sonderpaed-

Foerderung.pdf

[7] Ainscow, M., Booth, T. \& Dyson, A. (2006). Improving schools, developing inclusion. London: Routledge.

[8] Proost, K. (in press). Inklusion und individuelle Förderung: Eine Frage des Menschenbildes?! [Inclusion and individual support: a qustion of one's view of man?!] Jahrbuch für Allgemeine Didaktik, 4.

[9] Dewey, J. (1916/2009). Democracy and education. Radford: Wilder Publications.

[10] Gruber, H. \& Stöger, H. (2011). Experten-NovizenParadigma [Expert novice paradigm]. In E. Kiel \& K. Zierer (Eds.), Basiswissen Unterrichtsgestaltung [Basic knowledge teaching] (pp. 247-264). Baltmannsweiler: Schneider.

[11] Kunter, M. \& Pohlmann, B. (2009). Lehrer [Teachers]. In E. Wild \& J. Möller (Hrsg.), Pädagogische Psychologie [Educational psychology] (pp. 262-282). Heidelberg: Springer.

[12] Pajares, M.F. (1992). Teachers' beliefs an educational research: Cleaning up a messy construct. Review of Educational Research, 62, 307-332.

[13] Woolfolk Hoy, A., Davis, H. \& Pape, S. (2006). Teachers' knowledge, beliefs, and thinking. In P.A. Alexander \& P.H. Winne (Eds.), Handbook of educational psychology (pp. 715-737). Mahwah: Lawrence Erlbaum.
[14] Eder, F. (2011). Klassenklima [Class climate]. In E. Kiel \& K. Zierer (Eds.), Basiswissen Unterrichtsgestaltung [Basic knowledge teaching] (pp. 113-127). Baltmannsweiler: Schneider.

[15] Resnick, M. et al. (1997). Protecting adolescents from harm, Findings from the national longitudinal study on adolescent health. Journal of the American Medical Association, 278 (10), 823-832.

[16] Cohen, L., Manion, L. \& Morrison, K. (2007). Research methods in education. 6th ed. New York: Routledge.

[17] Fleishman, E.A. (1998). Fleishman Job Analysis Survey: F-JAS. Potomac/MD: Management Research Institute.

[18] Fahrmeir, L., Kneib, T. \& Lang, L. (2009). Regression. Modelle, Methoden und Anwendungen [Regression. Models, methods and practices]. 2nd ed. Berlin: Springer.

[19] Lamnek, S. (2010). Qualitative Sozialforschung [Qualitative social research]. 5th ed. Weinheim: Beltz.

[20] Mayring, P. (2010). Qualitative Inhaltsanalyse. Grundlagen und Techniken [Qualitative content analysis. Principles and techniques]. 11th ed. Weinheim: Beltz.

[21] Bos, W. (1989). Reliabilität und Validität in der Inhaltsanalyse [Reliability and validity in content analysis]. In W. Bos \& C. Tharnai (Eds.), Angewandte Inhaltsanalyse in Empirischer Pädagogik und Psychologie [Applied content analysis in empirical education and psychology] (pp. 211-228). Münster, New York: Waxmann.

[22] Benkmann, R. (2011). Professionalisierung von Sonderschullehrkräften für den Gemeinsamen Unterricht“ [Professionalization of special needs teachers]. Schulpädagogik heute, 2 (3), 1-16.

[23] Hallahan, D.P., Kauffman, J.M. \& Pullen, P.P. (2012). Exceptional learners. 12th ed. Upper Saddle River/NJ: Pearson.

[24] van Dick, R. \& Wagner, U. (2001). Stress and strain in teaching: a structural equation approach. British Journal of Educational Psychology, 71, 243-259.

[25] McGuire, J.M., Scott, S.S. \& Shaw, S.F. (2006). Universal design and its application in educational environments. Remedial and Special Education, 27 (3), 166-175.

[26] OECD (Organisation for Economic Co-operation and Development) (2004). Attracting, developing and retaining effective teachers - country backround reports. Accessed April 2. http://www.oecd.ord/document/50/0,2340,en_ 2649_201185_31711602_1_1_1_1_1,00.html

[27] Avramidis, E., Bayliss, P. \& Burden, R. (2000). Student teachers' attitudes towards the inclusion of children with special educational needs in the ordinary school. Teaching and Teacher Education, 16, 277-293. 
International Journal of Technology and Inclusive Education (IJTIE), Special Issue Volume 1, Issue 2, 2014

[28] Avramidis, E. \& Norwich, B. (2002). Teachers' attitudes towards integration/inclusion: a review of the literature. European Journal of Special Needs Education, $17,129-147$. 